\title{
LAS COMPETENCIAS PERSONALES Y SOCIALES EN LAS COLONIAS MUSICALES
}

\section{Diego Calderón Garrido, Josep Gustems Carnicer \& Caterina Calderón Garrido}

\author{
Universidad de Barcelona \\ dcalderon@ub.edu, jgustems@ub.edu y ccalderon@ub.edu
}

\begin{abstract}
Las colonias musicales son una propuesta educativa que combina la educación musical con la pedagogía del ocio. Este artículo, a través de una metodología cuantitativa pretende describir el perfil de alumnado y analizar las competencias personales (autoestima, creatividad y pensamiento constructivo/inteligencia emocional) y sociales (empatía y liderazgo) de una muestra total de 234 alumnos de colonias musicales de dos comunidades autónomas, mediante la aplicación de los cuestionarios RSES, CREA, CTI, TECA y LID. En base a estos resultados incluimos una serie de indicaciones y actividades que permitirían el desarrollo de dichas competencias.

Palabras clave: colonias musicales, competencias sociales, competencias personales, pedagogía del ocio

Music camps are an educational project that combines musical education and leisure education. This article, using a quantitative methodology, pretends to describe the profile of the students and analyse personal skills (self-esteem, creativity and constructive thought/emotional intelligence) and social skills (empathy and leadership) from and extract of 234 students of music camps from two regions of Spain, using the following quizzes: RSES, CREA, CTL, TECA and LID. Based on the results, we include a series of indications and activities that could benefit the development of these competencies.
\end{abstract}

Keywords: music camps, social skills, personal skills, leisure education

\section{INTRODUCCIÓN}

Las colonias musicales son una propuesta formativa destinada a los menores de edad en la cual se combina la educación musical con la pedagogía en el ocio. Las colonias pretenden el desarrollo de aptitudes musicales mediante el aprendizaje instrumental (Rusinek, 2006), respaldado por juegos y actividades de ocio. Así pues, los asistentes a dichas colonias reciben clases de música de profesores cualificados, durante aproximadamente cinco horas diarias a lo largo de una semana, y son guiados en su tiempo libre por monitores especializados.

Las características principales y diferenciadoras de las colonias musicales respecto a otras propuestas centradas en la educación musical se derivan de la convivencia entre los diferentes agentes educativos. Las personas implicadas en dichas colonias en España representan en la actualidad unos 2000 alumnos, 145 profesores y 100 monitores de tiempo libre (Calderón, Gustems \& Calderón, 2014).

A pesar de esta notable afluencia y a diferencia de otros ámbitos educativos, no se ha realizado ningún estudio formal sobre las competencias personales y sociales involucradas en tales colonias. En este sentido, consideramos necesario conocer dichas competencias para, una vez establecidos los objetivos pedagógicos presentes en unas colonias musicales (Calderón, Gustems \& Calderón, 2014), asegurar la concordancia entre unas y otros y, en caso necesario, reformular la orientación de dichas colonias musicales.

Partimos de la definición de Perrenoud (2007) de “competencia”, la cual es entendida como una aptitud que permite movilizar recursos cognitivos. Además de esto debemos de tener en cuenta que su ejercitación se realiza a través de complejas operaciones mentales, por lo que las capacidades estarán expresadas por los contenidos que deberán desarrollarse por el alumnado. Por su parte, Parcerisa (2007) aplica este concepto a la educación musical, y despliega las distintas competencias susceptibles de vincularse con este arte, siguiendo las indicaciones de la LOE (2006) y la Generalitat de Catalunya respecto a las competencias básicas (DOGC nº 4915, 29-6-2007, p. 21823).

Aunque la pedagogía plantea el estudio pormenorizado y sistemático de la evaluación de competencias (Cano, 2005), para comprender y evaluar las competencias personales y sociales que 
se desarrollan en la educación musical deberemos acudir los conocimientos que en este campo aporta la evaluación psicológica y la psicología social. Para ello nos serviremos del marco teórico derivado del DSM-IV-TR y de algunas pruebas diagnósticas más adecuadas a los ítems que se pretende evaluar. En cualquier caso, las competencias que aquí analizamos se muestran como las capacidades que permitirán al alumnado enfrentarse al proceso educativo con cierto nivel de calidad y eficacia (Bisquerra \& Pérez, 2007). De esta forma nos centraremos en competencias personales tales como la autoestima, la creatividad y la inteligencia emocional; y en competencias sociales tales como la empatía y el liderazgo.

El análisis de cada una de estas competencias transversales (Giráldez, 2011) permitirá poder tener una visión mucho más completa de la realidad intangible en las colonias musicales y de las decisiones a tomar en cuanto a la organización de las sesiones de trabajo en el futuro. Además, debemos tener en cuenta que estas competencias se insertan dentro de los tres principales dominios en que Hargreaves y North (1999) presentan las funciones de la música para el ser humano: el ámbito cognitivo, el emocional y el social. En este sentido, las colonias musicales son un espacio privilegiado para poner en práctica las competencias individuales y grupales, puesto que las actividades musicales y de ocio lejos de la familia así lo permiten.

Así pues, y acercándonos a cada una de dichas competencias, conocer la autoestima que tiene los asistentes a unas colonias de música resulta trascendental al tratarse, como veremos más adelante, de alumnos entre los 6 y 17 años de edad, con los posibles problemas derivados de los cambios en el auto concepto y la autoestima, especialmente en los adolescentes. Dichos posibles problemas se pueden ver acentuados con los desajustes derivados del estudio musical descritos por Dalia (2008) fruto de la búsqueda del perfeccionismo y del dicotomismo presente en el perfil de los músicos. Por otro lado, y en sentido contrario, los estudios de Trusty y Oliva (1994) demuestran cómo la participación en actividades musicales está estrechamente ligada con el desarrollo positivo del auto concepto.

Por lo que respecta a la creatividad, existe una amplia bibliografía que la vincula con la educación artística y musical. La creatividad es un ámbito de conocimiento teórico-práctico transversal, con carácter sistémico, dedicado al estudio del potencial creativo de las personas, los procesos y productos creativos, los lugares y contextos que propician la creatividad, y la aplicación de determinadas técnicas para desarrollarla (Runco, 2010).

Centrándonos en los contextos citados, las colonias, las cuales se desarrollan desde una actitud lúdica en un ambiente elegido por sus participantes (Calderón, 2013), la creatividad encontraría, potencialmente, un espacio ideal en el que poder fomentar su desarrollo. Así pues, al menos en teoría, los alumnos realizarán actividades artísticas más creativas que las que puedan realizar dentro de un aula.

En ese mismo contexto descrito, en el cual la intensidad de las actividades marcan las relaciones interpersonales (Colomer, 1975), la inteligencia emocional juega el papel de piedra angular sobre la que pivotan tanto las propias emociones de cada alumno como su capacidad de gestionar estas emociones con las de sus compañeros (Goleman, 1995). Por tanto, conocer la inteligencia emocional de los asistentes a unas colonias nos ayudará a gestionar dichas emociones para enfatizar o amortiguarlas en función de las necesidades y de cada momento. Estas emociones que estamos describiendo se conjugan con las descritas por Lamont (2012) en su estudio relativo a la interpretación y audición musical realizada en jóvenes, en este caso universitarios. En cualquier caso, en contextos educativos el efecto de la educación emocional puede abarcar las relaciones interpersonales, el clima de la clase, disciplina o rendimiento académico así como la prevención de conductas violentas u acciones que puedan comportar estrés o estados depresivos en el alumnado (Gustems \& Calderón, 2005). Así pues, la gestión de todas estas emociones repercutirá en el proceso de aprendizaje y, en definitiva, en el producto musical. 
Por otro lado, y al tratarse de un contexto educativo basado en la convivencia y el trabajo en grupo, tanto desde la perspectiva musical como social, competencias sociales tales como la empatía o la capacidad de liderazgo resultan claves. El desarrollo de dichas competencias ayudarán a entender el trabajo en grupo (Davis, 2005), característica intrínseca de unas colonias musicales. En cualquier caso, de todas las competencias sociales, nos hemos centrado en dos de ellas: la empatía y el liderazgo.

En el caso de la empatía, estamos ante una destreza que nos permite interactuar eficazmente con la sociedad que nos rodea, tanto en un grupo musical como con los compañeros de habitación y juegos (Letourneau, 1981). Por su parte, la competencia social referida al liderazgo toma un especial protagonismo. Así podemos hablar del líder del grupo, del líder de la actividad, del líder del dormitorio, del líder de la formación musical, etc. Además debemos ser conscientes que dicha competencia se relaciona estrechamente con la motivación, la innovación y, en definitiva, con los logros académicos (Álvarez, 2001). En este sentido, la concepción romántica de considerar que los buenos lideres (como por ejemplo, los directores musicales) "nacen" y no se hacen ha sido refutada por múltiples estudios actuales (Varvaigou \& Durrant, 2011). Ambas competencias sociales resultan de vital importancia en la etapa en la que asisten los alumnos a unas colonias musicales, ya que, en su mayoría, se trata de preadolescentes y adolescentes. En dichas edades las relaciones interpersonales toman especial relevancia, de forma que el sentimiento de pertenencia a un grupo se convierte en una necesidad primordial (Souza, 2009).

El objetivo de este trabajo es describir un perfil del alumnado mediante datos sociodemográficos y evaluar las competencias personales y sociales en una muestra relevante de alumnado asistente a colonias musicales, para poder tomar, si es el caso, decisiones organizativas respecto a la dinámica que se pueda generar en dichas colonias.

\section{METODOLOGÍA}

\section{Diseño}

Se trata de un estudio descriptivo -o exploratorio- post hoc con carácter prospectivo a partir de la recolección de datos cuantitativos, mediante la aplicación de unos instrumentos de evaluación de competencias de reconocida fiabilidad. Dichos instrumentos nos han permitido analizar las dimensiones formativas presentes en unas colonias musicales a partir de las competencias personales e interpersonales que los alumnos han mostrado.

\section{Instrumentos}

$1^{\text {a) }}$ Hemos establecido el perfil de los asistentes a unas colonias musicales a través del cuestionario de Hollingshead (1975) y un cuestionario creado ad hoc. El análisis de los resultados de este cuestionario, el cual era de obligada respuesta antes de proceder al resto de ellos, permitió relacionar los resultados en función de las variables de género y edad que expondremos más adelante.

$2^{\text {a }) ~ H e m o s ~ e v a l u a d o ~ l a s ~ c o m p e t e n c i a s ~ p e r s o n a l e s ~ t a l e s ~ c o m o ~ l a ~ A u t o e s t i m a ~ a ~ t r a v e ́ s ~ d e ~ l a ~ E s c a l a ~}$ de Autoestima (RSES); la Creatividad a través del Cuestionario de Creatividad (CREA) y el Pensamiento Constructivo y la Inteligencia Emocional a través del Inventario de pensamiento constructivo. Una medida de la inteligencia emocional (CTI).

\section{Escala de Autoestima de Rosenberg (RSES) (Rosenberg, 1989).}

La escala de autoestima de Rosenberg es un autoinforme de 10 ítems con formato tipo Likert de 4 puntos. Cinco de los ítems puntúan en sentido positivo, mientras que los otros cinco lo hace en sentido negativo. Las puntuaciones globales presentan un rango de 10 a 40 puntos (10 indicaría más baja autoestima y 40 la más alta). El RSES presenta buenas características psicométricas, su consistencia interna oscila entre 0,77 y 0,87 (Rosenberg, 1989), y su fiabilidad test- retest es de 0,85 a las dos semanas, y de 0,73 a los siete meses (Wylie, 1989). En población española, ha demostrado 
una consistencia interna de 0,88 (Baños y Guillén, 2000). La Escala de Rosenberg es una medida clásica utilizada internacionalmente en las últimas décadas y aplicada a muestras de diversos países así como a la población española (Atienza, Moreno y Balaguer, 2000).

Cuestionario de creatividad (CREA) (Corbalán, Martínez, Donolo, Alonso, Tejerina y Limiñana, 2003).

El CREA ofrece una medida indirecta de la creatividad, escoge como procedimiento de medida la capacidad del sujeto para elaborar preguntas. La prueba utiliza una lámina a partir de la cual los participantes deben formular la mayor cantidad de interrogantes posibles en un tiempo establecido. El cuestionario ofrece una puntuación total centil en un rango de 0 a 100 . Una puntuación inferior a 30 puntos indicaría bajo nivel de creatividad, una puntuación entre 31 y 70 puntos indicaría moderada creatividad, y una puntuación superior a 71 indicaría una excelente creatividad. Su fiabilidad testretest es 0,87 y su alfa de Cronbach 0,79 .

Inventario de pensamiento constructivo. Una medida de la inteligencia emocional (CTI) (Epstein, 2001).

Compuesto por 108 ítems que evalúan el pensamiento constructivo y la inteligencia emocional. El instrumento está jerárquicamente organizado y ofrece información en tres niveles. El nivel más general consiste en una escala global que se denomina PCG (Pensamiento Constructivo Global). Las personas con altas puntuaciones en PCG tienen una estructura de pensamiento flexible, adaptan sus modos de pensar a las modalidades de diferentes situaciones, se aceptan bien a sí mismas y a los demás, suelen establecer relaciones gratificantes y generalmente tienden a concebir a otros el beneficio de la duda. El siguiente nivel de generalidad lo componen seis escalas principales que miden las formas básicas de pensamiento constructivo o destructivo que, a su vez, contienen 15 subescalas. Los componentes del pensamiento constructivo son el afrontamiento emocional y el afrontamiento conductual. Los componentes del pensamiento destructivo son el pensamiento categórico, pensamiento supersticioso, pensamiento esotérico y el optimismo ingenuo (Epstein, 2001). Los coeficientes de fiabilidad de las escalas son adecuados. Además de la aplicación de la técnica factorial, la validez del constructo del CTI se apoya en gran variedad de estudios tales como las relaciones de las escalas con tests de personalidad, conducta observada en laboratorio, tests de inteligencia, éxito en el trabajo, bienestar emocional y físico, etc. Así pues, y con la excepción de la escala de pensamiento supersticioso, el CTI posee una alta validez factorial tanto a nivel de elementos o escalas como de facetas. Se consideraría una puntuación media aquella situada entre la puntuación $\mathrm{T}$ de 45 a 55 (DT 10). Las situadas entre la puntuación T de 56 a 65 se considerarían altas (corresponderían a percentiles entre 70 a 93). Las situadas entre la puntuación T entre 35 a 44 se considerarían bajas (corresponderían a percentiles entre 7 a 30). Las puntuaciones $\mathrm{T}$ en Deseabilidad superiores a 70 e inferiores a 30 en Validez, invalidarían la aplicación del instrumento (Epstein, 2001).

$3^{a}$ ) Hemos evaluado las competencias sociales tales como la empatía a través del Test de empatía cognitiva y afectiva (TECA); y la capacidad de liderazgo a través del Cuestionario de capacidad de liderazgo (LID).

Test de empatía cognitiva y afectiva (TECA) (López-Pérez, Fernández-Pinto \& Abad, 2008).

Este test consiste en un cuestionario con 33 ítems subdivididos en 4 escalas: adopción de perspectivas, comprensión emocional, estrés empático y alegría empática. También proporciona un índice global de empatía (Oceja, López-Pérez, Ambrona, y Fernández, 2009). La fiabilidad test-retest fue de 0,86. El alfa de Cronbach puntuó de 0,70 a 0,86.

Cuestionario de capacidad de liderazgo (LID) (Ávila de Encío, 2010).

El cuestionario de capacidad de liderazgo es un autoinforme de 15 ítems con formato tipo Likert de 4 puntos, diseñado para evaluar la capacidad de liderazgo de los estudiantes. El cuestionario ofrece 
una puntuación total en un rango de 10 a 40, siendo la puntuación de menos de 19 puntos la más baja en liderazgo y la de 40 o más, la puntuación que indicaría mayores capacidades de liderazgo.

\section{Muestra y procedimiento}

Todos estos cuestionarios fueron contestados de forma presencial en diversos turnos de colonias musicales de dos comunidades autónomas, con un total de 234 participantes, en el verano de 2012. Los cuestionarios se distribuyeron el último día de la colonia. Previamente se informó tanto a los alumnos como a sus respectivos tutores legales sobre dicho estudio y los procedimientos de evaluación. A todos se les informó de que su participación era completamente voluntaria y que podían escoger entre participar, no participar, o no responder a algunas de las preguntas específicas que les incomodasen. Todos ellos firmaron el consentimiento informado. Se garantizó el anonimato y la confidencialidad mediante el uso de códigos para los datos obtenidos. El estudio se enmarcó dentro de las directrices del Informe Belmont (Comisión Nacional para la Protección de los Sujetos Humanos de Investigación Biomédica y del Comportamiento, 1978) y del Código de buenas prácticas de investigación de la Universidad de Barcelona (2010). Para el procesamiento y análisis de los datos se utilizó el Statistic Package for Social Science (SPSS), versión 16.0.

Se obtuvo una muestra válida total de 194 participantes en el caso del cuestionario de Autoestima (RSES), 196 en el cuestionario de creatividad (CREA), 159 en el cuestionario de inteligencia emocional y pensamiento constructivo (CTI), 182 participantes en el cuestionario de empatía (TECA) y 179 en el cuestionario de liderazgo (LID).

\section{RESULTADOS}

En primer lugar, y para poder establecer el perfil del alumnado de unas colonias musicales y a su vez centrar la muestra de participantes en los cuestionarios que en esta investigación hemos empleado, presentamos los datos sociodemográficos. De esta forma, y haciendo una presentación de todos los cuestionarios contestados, podemos afirmar que la mayoría de los participantes en unas colonias musicales son de género femenino, en concreto el $62,8 \%(n=147)$, mientras que el $37,2 \%(n=87)$ es de género masculino.

Respecto la edad, en unas colonias musicales hay alumnos con edades comprendidas entre los 6 y los 17 años. En nuestro trabajo, la edad media es de 13 años, aunque la moda se sitúa en los 14 años, con el $14,7 \%$ de respuestas.

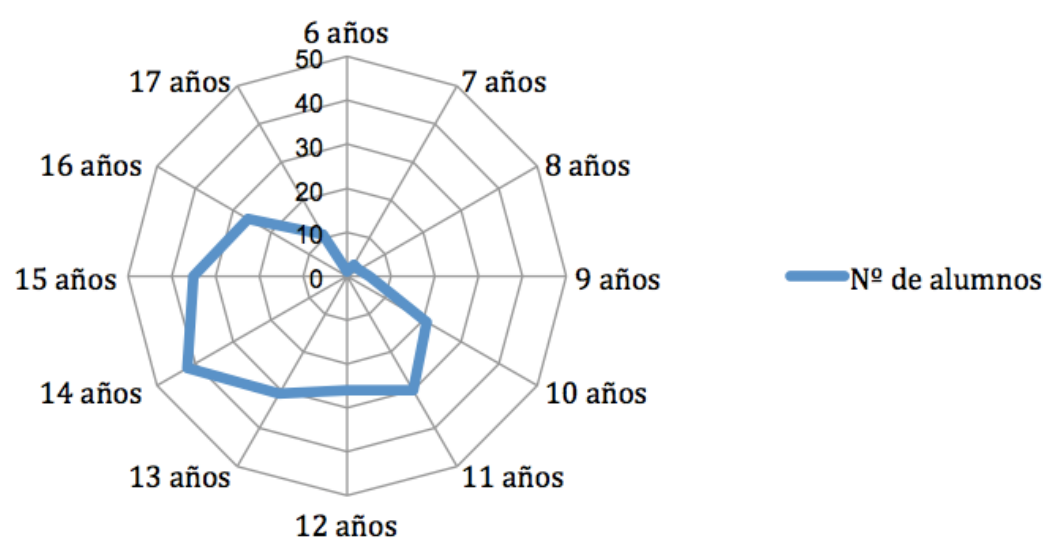

Fig. 1: Edad del alumnado

Respecto al contexto familiar del alumnado, podemos apreciar que el 22,3\% $(n=46)$ no tienen hermanos, el 53,5\% $(n=110)$ tiene un hermano, el 19,4\% $(n=40)$ dos hermanos, el 3,8\% $(n=8)$ tres hermanos y el $1 \%(n=2)$ del alumnado tiene cinco hermanos. Tanto la media como la moda se establecen en, aproximadamente, 1 hermano. 
Centrándonos en la residencia habitual del alumnado, observamos como el 37,6\% $(n=77)$ vive en una pequeña ciudad, el 29,3\% $(n=60)$ vive en un pueblo, el $28,8 \%(n=59)$ lo hace en una gran ciudad y el 4,3\% $(n=9)$ vive en las afueras de una ciudad.

El nivel socioeconómico familiar (NSE), en base a los criterios establecidos por Hollingshead (1975), muestra que los asistentes tienen un nivel socioeconómico familiar medio ( $M=33$, DT = 11). En concreto el 4,2\% $(\mathrm{n}=10)$ son de nivel socioeconómico alto, el 29,9\% $(\mathrm{n}=70)$ NSE medio-alto, el 21,4\% ( $n=50)$ NSE medio, el 21,4\% $(n=50)$ NSE medio-bajo, y el 9,4\% $(n=22)$ NSE bajo, y carecemos de esa información en el $13,7 \%(n=32)$ de la muestra.

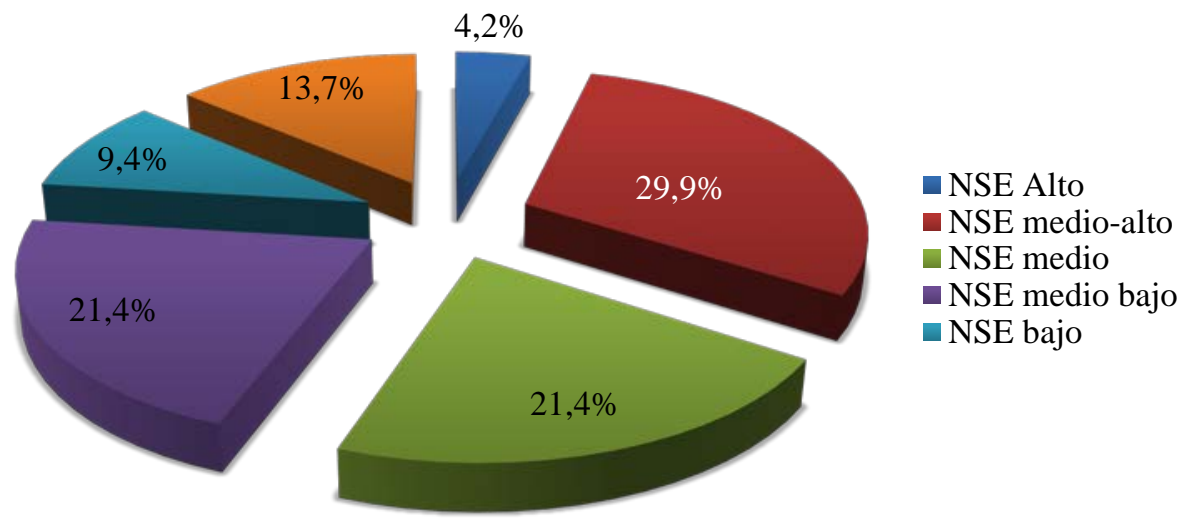

Fig. 2: Nivel socioeconómico familiar

En el caso del instrumento musical que toca el alumnado, dicho dato es muy diverso, de forma que el instrumento predominante corresponde a teclado, en concreto al piano, con un $32,1 \%(n=75)$ de alumnos que estudian dicho instrumento. El 23,1\% $(n=54)$ del alumnado estudia instrumentos de la familia de viento madera, el $18,3 \%(n=43)$ son instrumentistas de cuerda pulsada, el $15 \%(n=35)$ hacen lo propio con instrumentos de cuerda frotada, el 4,7\% ( $\mathrm{n}=11)$ del alumnado estudia principalmente instrumentos de percusión, y el 3,8\% $(n=9)$ lo hace con instrumentos propios del viento metal. Finalmente, solo el 3\% $(\mathrm{n}=7)$ del alumnado, manifestó que su instrumento principal era la voz.

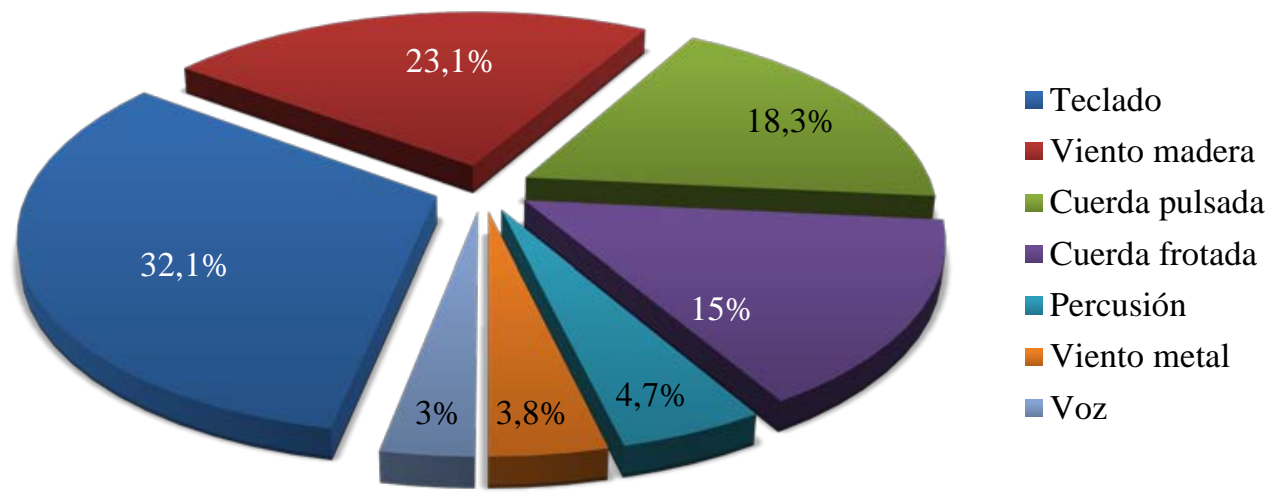

Fig. 3: Instrumento principal del alumnado

En lo que se refiere al centro donde estudian dicho instrumento principal, la mayoría del alumnado, un $62,3 \%(n=146)$ estudia en una escuela de música durante el curso lectivo, mientras que el 24,8\% $(n=58)$ lo hace en un conservatorio. El 7,7\% $(n=18)$ de los encuestados estudia con un profesor particular mientras que el 2,6\% $(n=6)$ son autodidactas. Finalmente, el 2,6\% $(n=6)$ ofreció "otras" respuestas que incluían "aulas de cultura”, “actividades extraescolares en el colegio” y “cau/Scout”. 


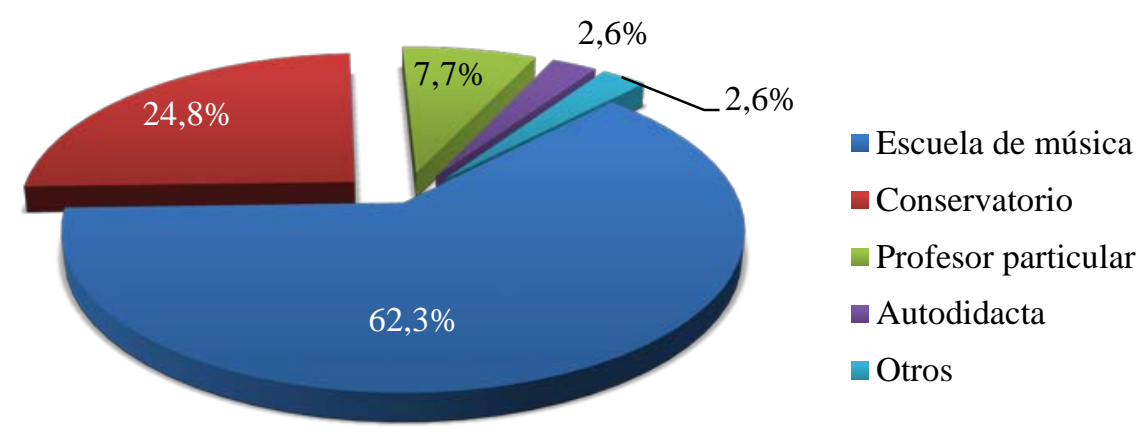

Fig. 4: Centro de estudios musicales

Respecto a los años de estudio del instrumento, se percibe un rango entre uno y once años de experiencia, con una mayor frecuencia de respuesta entre los tres y los siete años de estudio. En cualquier caso, la media es de poco más de 5 años, mientras que la moda es de 4 años. Este dato nos ofrece una perspectiva del nivel musical aproximado sobre el que se trabaja en las colonias musicales, de forma que destacan una mayoría de estudiantes de final de grado elemental y primeros cursos del grado profesional.

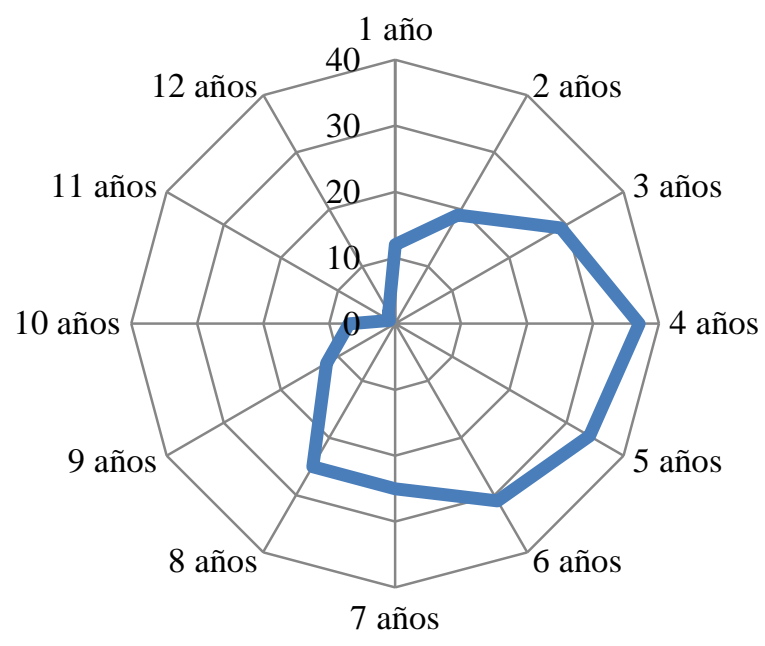

$\mathrm{N}^{\mathrm{o}}$ de alumnos

Fig. 5: Años de estudio del instrumento

Tal como describimos en la introducción, las colonias musicales se basan en clases colectivas y con diversas formaciones musicales, en este sentido, destacamos como la mayoría del alumnado, el $65,5 \%(n=153)$ toca habitualmente en grupos, mientras que el 34,5\% $(n=81)$ restante no lo hace. De los alumnos que contestaron afirmativamente, el 39,7\% $(n=60)$ lo hacían en grupos de música moderna, el 31,8\% ( $n=48)$ en grupos de música clásica, y el 24,5\% $(n=37)$ contestó que tocaban en uno o más grupos de diversos estilos. Finalmente, un $2 \%(\mathrm{n}=3)$ lo hacía en grupos de música tradicional y otro $2 \%(\mathrm{n}=3)$ marcaron la casilla referente a "otros". 


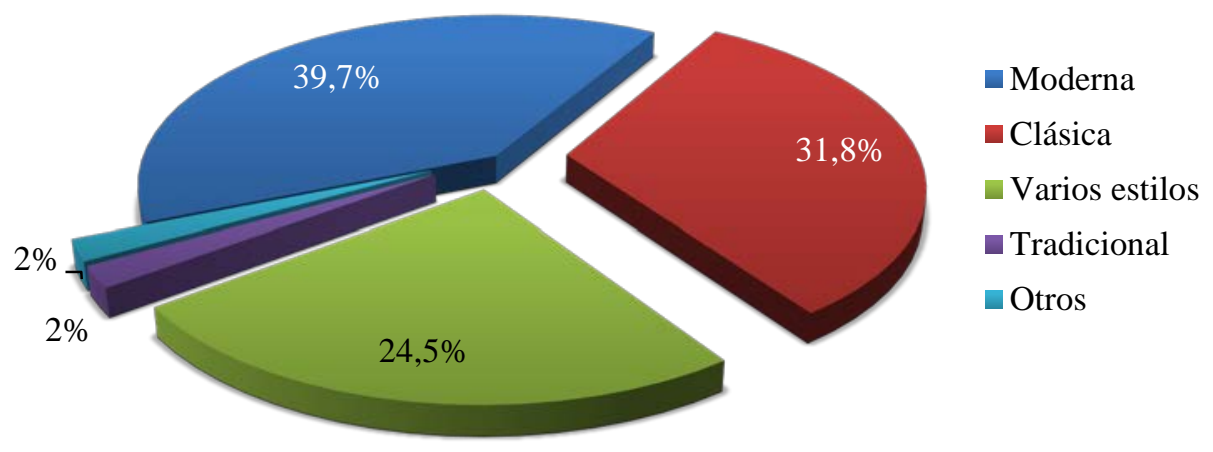

Fig. 6: Estilos de música que interpretan habitualmente

Respecto a los años de asistencia a las colonias, la muestra evaluada está entre un año y los diez años de asistencia. En cualquier caso la media es de dos años y la moda de uno.

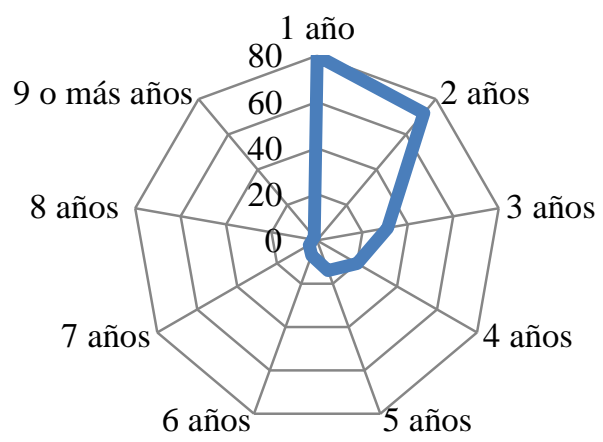

$\mathrm{N}^{\mathrm{o}}$ de alumnos

Fig. 7: Años asistiendo a colonias musicales

Respecto a la participación en otros tipos de colonias o campamentos, la mayoría del alumnado, el $63,9 \%(n=150)$ ha asistido alguna vez a otra tipología de colonias, mientras que el $36,1 \%(n=84)$ no lo ha hecho nunca. De los que sí han participado, remarcamos como el 25\% (n = 38) ha asistido a colonias o campamentos de idiomas, el 22,3\% $(n=33)$ en tipologías relacionadas con el deporte, y con el mismo porcentaje en tipologías relacionadas con el cau/scout. Otro 22,3\% $(n=33)$ del alumnado ha asistido a varios campamentos o colonias de diferentes tipologías y el $8,1 \%(n=13)$ del alumnado ha asistido a colonias o campamentos de alguna otra orientación artística, como es el caso del cine o el teatro.

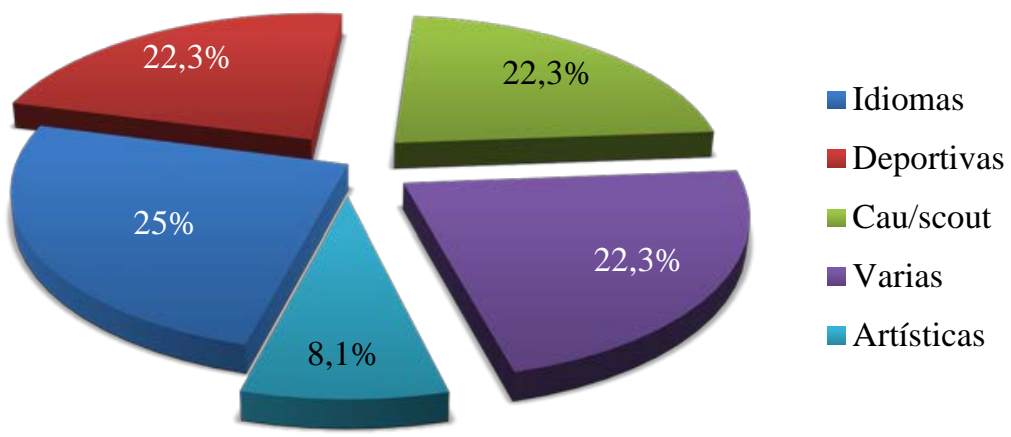

Fig. 8: Tipología de colonias y campamentos en los que han participado

Por tanto, y haciendo una síntesis de estos datos, concretamos que el perfil tipo de un asistente a unas colonias musicales es el de una chica de 14 años de edad, de un nivel socioeconómico medio, que vive en una ciudad pequeña y tiene otro hermano. Respecto al instrumento que practica es el teclado o en su defecto algún instrumento de viento madera, y acude una escuela de música durante 
el invierno desde hace cuatro años. Dicha alumna toca habitualmente en grupos de música moderna. Con anterioridad a las colonias de música, ha participado en otras colonias de idiomas.

Respecto a los cuestionarios que tienen como objetivo evaluar las competencias personales y sociales del alumnado en unas colonias musicales, se muestran a continuación los datos descriptivos de los diferentes cuestionarios utilizados para este fin.

En lo que se refiere a la autoestima, si describimos las puntuaciones de la Escala de Autoestima de Rosenberg (RSES), tal como reflejamos en la siguiente figura, los 194 participantes que completaron dicho cuestionario obtuvieron una puntuación directa global de 26,7 $(\mathrm{SD}=2,0)$ lo que indica que se autodefinen como personas con una buena autoestima.

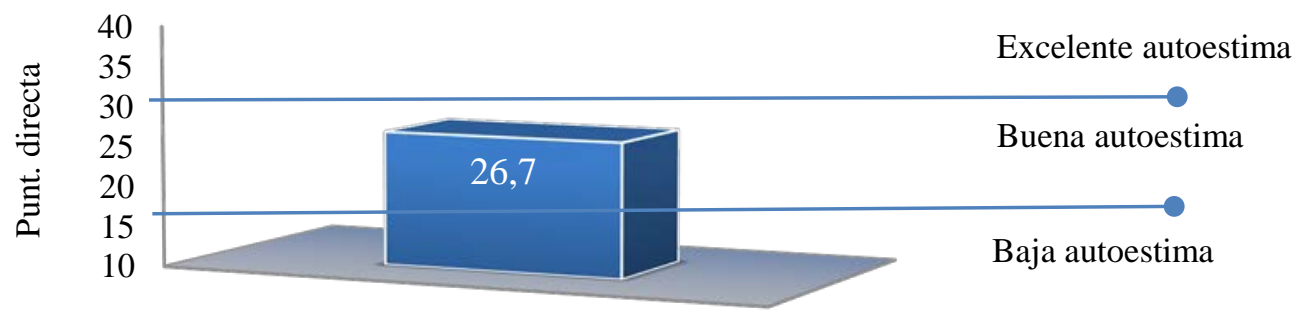

Fig. 9: Puntuaciones directas de la Escala de Autoestima (RSES)

En función de la puntuación obtenida, solo el 0,5\% $(\mathrm{n}=1)$ de los participantes muestra una autoestima baja; mientras que el 90,7\% $(\mathrm{n}=176)$ señala que tiene una buena autoestima; y el 8,8\% $(n=17)$ de los participantes mostraron una excelente autoestima.

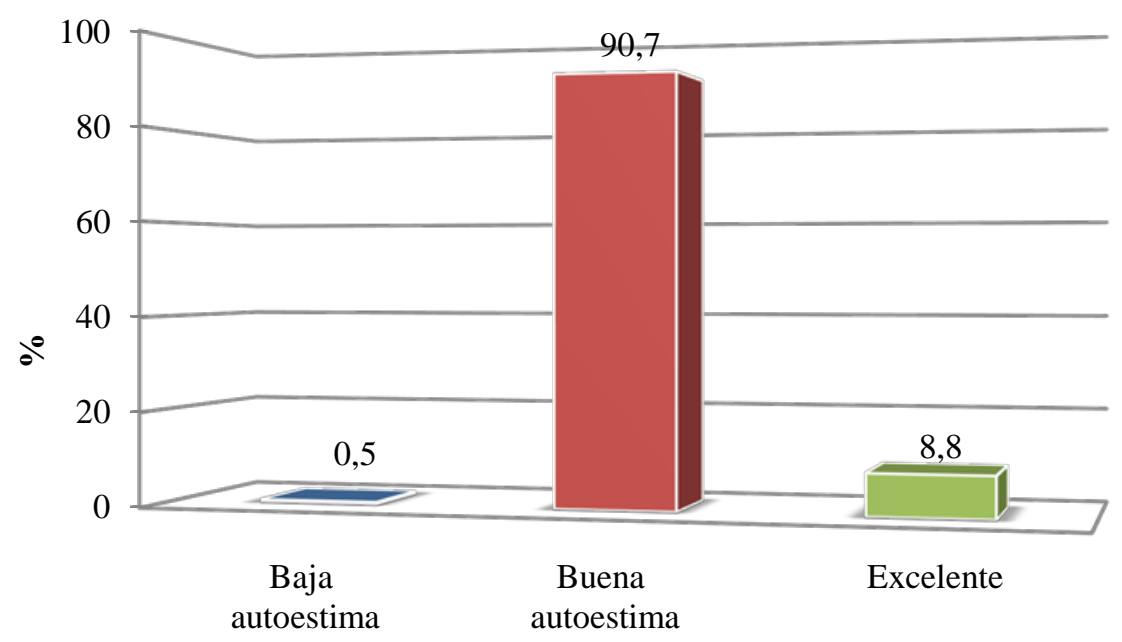

Fig. 10: Puntuaciones categorizadas en la Escala de Autoestima (RSES)

Si realizamos un análisis en función del género, percibimos como los chicos presentan puntaciones globales similares en RSES, media de 26,8 ( $\mathrm{SD}=2,1)$, a las chicas, media de 26,7 (SD = 1,9). En cualquier caso, tanto hombres como mujeres presentan una buena autoestima, diferencias que no son estadísticamente significativas entre ambos sexos $(t=0,381, p=0,704)$.

En función de la edad podemos distinguir como, en general, los menores de 13 años presentan puntaciones similares en autoestima en el RSES, media de 26,5 (SD = 1,9), a las obtenidas por los mayores de 13 años, media 26,9 (SD = 2,0). Tanto los mayores como los menores, en conjunto, muestran buena autoestima, las diferencias entre ambos grupos no son estadísticamente significativas $(\mathrm{t}=-1,277, \mathrm{p}=0,203)$. 
De esta forma, y en base a esto, podemos afirmar que los resultados obtenidos por los chicos/as de las colonias musicales los describen como personas con una buena autoestima. Consideramos que la muestra analizada no plantea los problemas descritos en la introducción, tales como los derivados del dicotomismo y el perfeccionismo, en la etapa de estudiante de música. Respecto a otros estudios de autoestima en jóvenes en actividades de ocio, valoramos que en ambos sexos la adecuación conductual, la aceptación social y la amistad íntima sean los mejores protectores de las conductas de riesgo para la salud. La competencia entre iguales, ya sea en el deporte o en actividades de ocio ejerce una influencia indirecta sobre las conductas de salud, siendo la participación en dichos eventos una variable mediadora en esta relación (Pastor, Balaguer y García-Merita, 2006).

Si nos centramos en la creatividad que muestran los alumnos en función del cuestionario de creatividad (CREA), los 196 participantes que participaron en el cuestionario obtuvieron una puntuación centil global de 54,1 (SD = 25,1) lo que indica que son personas moderadamente creativas. Si observamos las puntuaciones apreciamos que se produce una gran dispersión en los resultados dados por los estudiantes en un rango de 1 a 97, es por ello que obtenemos una media de 54,1 pero la mayoría de estudiantes (moda) obtienen una puntuación alrededor de 45 en el CREA.

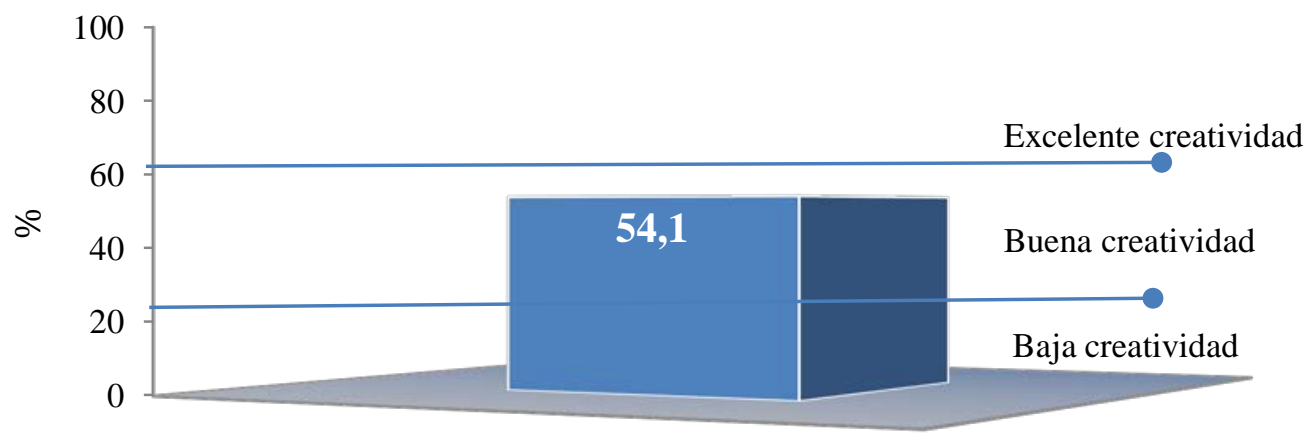

Fig. 11: Puntuaciones directas en el cuestionario de Creatividad (CREA)

Tal como reflejamos en la siguiente figura, en función de la categorización de la puntuación obtenida, el 14,3\% $(n=28)$ de los participantes muestran tener una baja creatividad; la mayoría de participantes, el 55,6\% $(n=109)$ de los participantes indican una moderada creatividad; y el 30,1\% $(\mathrm{n}=59)$ presentan una excelente creatividad.

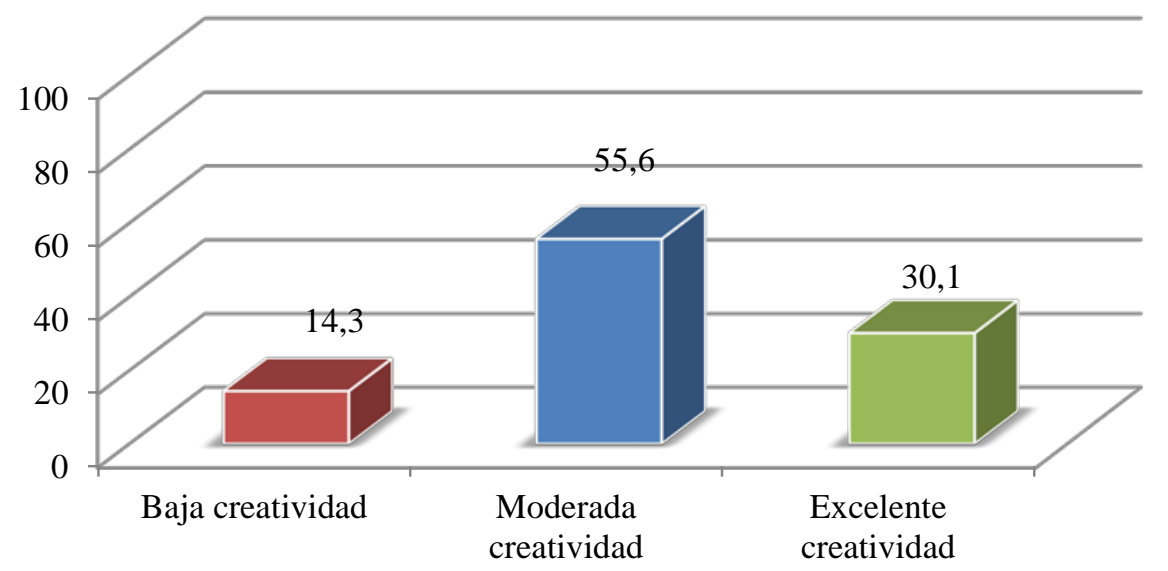

Fig. 12: Puntuaciones categorizadas en el cuestionario de creatividad (CREA)

En función del género, los hombres presentan puntaciones moderadas en el cuestionario de creatividad, media de 53,0 ( $\mathrm{SD}=22,8$ ), y las mujeres, media 54,8 ( $\mathrm{SD}=26,5)$. Hombres y mujeres 
muestran una puntuación similar en creatividad, diferencias que no son estadísticamente significativas $(t=-0,0491, p=0,694)$.

Respecto a las diferencias en función de la edad, en general los menores de 13 años presentan puntaciones globales similares en el cuestionario de creatividad, media de 51,6 (SD = 26,9), a las puntuaciones obtenidas por los mayores de 13 años, de media 56,2 (SD = 23,3). Tanto los mayores como los menores, en conjunto, muestran una moderada creatividad. Las diferencias entre ambos grupos no son estadísticamente significativas $(\mathrm{t}=-1,296, \mathrm{p}=0,196)$.

Tal como reflejan los datos obtenidos, a pesar de que las colonias se nos presentan como un ambiente ideal para el desarrollo del trabajo creativo, el alumnado asistente no muestra altos índices en dicha competencia. Por tanto, tratándose de una competencia artística, las actividades en las colonias musicales deberían fomentar aún más el desarrollo de la creatividad mediante actividades de improvisación y creación.

El desarrollo de la creatividad a altos niveles no siempre está asociado al bienestar ni al equilibrio de la personalidad ni a rasgos específicos, sino que los resultados a menudo son diversos e incluso discrepantes (Sternberg \& Lubart, 1997), aunque, de forma general, se considera a los alumnos más creativos como los que presentan mayor complejidad, impulsividad, falta de disciplina, autovaloración, tolerancia a la ambigüedad, extraversión, apertura a la experiencia e incluso psicoticismo (Alonso, 2000). El desarrollo de la creatividad en el contexto de las colonias musicales se plantea como algo positivo, consecuencia natural del trabajo artístico dirigido y en libertad, aunque sin perseguir niveles excelentes en todos los participantes.

Respecto a la descripción de las puntuaciones del inventario de pensamiento constructivo (CTI), en la figura siguiente mostramos como los 159 participantes obtuvieron una puntuación $\mathrm{T}$ en el pensamiento constructivo global en el CTI de 51,30 (SD = 10,1) lo que indica que se autodefinen como personas con una buena inteligencia experiencial y emocional.

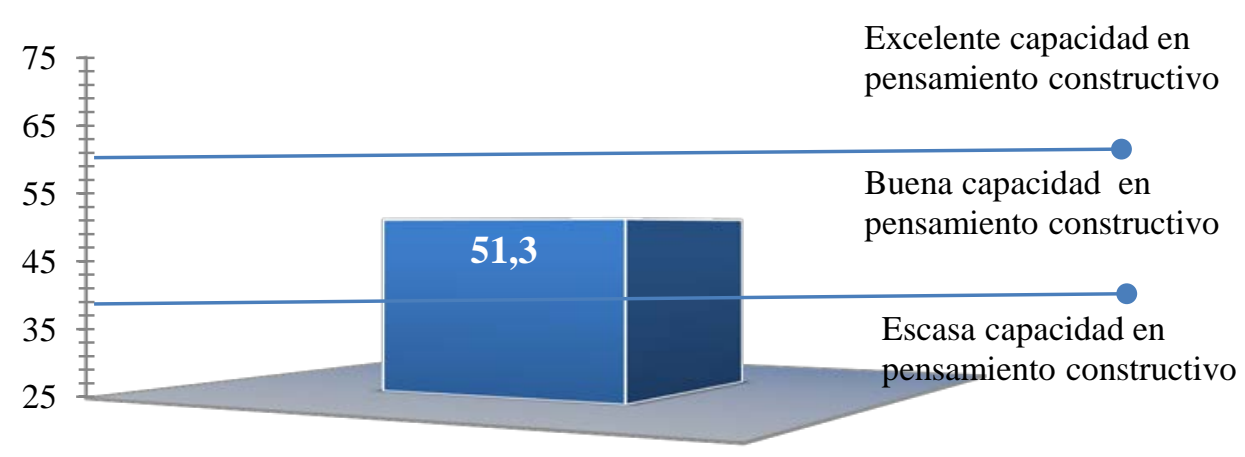

Fig. 13: Puntuación en la escala global PCG de pensamiento constructivo del inventario de pensamiento constructivo (CTI)

Tal como reflejamos en la siguiente figura, en función de las escalas generales, los participantes obtuvieron una puntuación de 49,88 (SD = 9,7) en la escala de afrontamiento emocional, de 51,03 $(\mathrm{SD}=10,1)$ en la escala de afrontamiento conductual, de 48,32 (SD = 10,2) en la escala de pensamiento mágico, de 49,09 $(\mathrm{SD}=11,4)$ en pensamiento categórico, de 53,81 $(\mathrm{SD}=8,4)$ en pensamiento esotérico y de 53,31 (SD = 11,1) en la escala de optimismo ingenuo.

En general, los participantes muestran puntuaciones más altas en optimismo ingenuo, pensamiento esotérico y afrontamiento conductual, lo que indica una tendencia a creer en fenómenos mágicos y supersticiones convencionales como la astrología y buenos o malos agüeros, cierta tendencia a evitar realidades desagradables, y a ser optimistas, enfatizar lo positivo, entusiastas, enérgicos y fiables, rápidos en acción. 


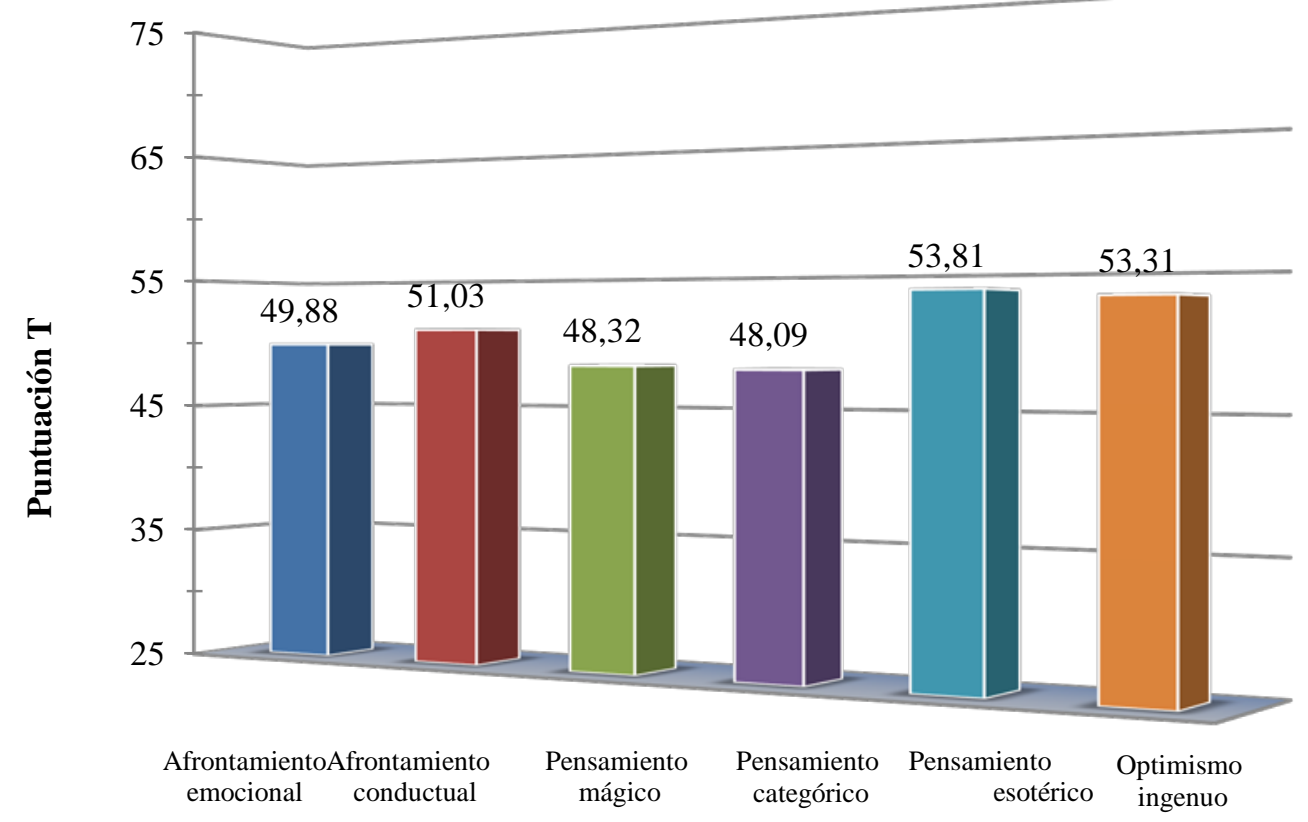

Fig. 14: Puntuaciones T en el Inventario de Pensamiento Constructivo (CTI)

Si analizamos las diferencias en función del género, observamos cómo, en general, los hombres presentan puntaciones globales en el pensamiento constructivo del CTI, media de 50,9 (SD = 10,9), y las mujeres, media 51,5 (SD = 9,6). Las puntuaciones obtenidas por hombres y mujeres son muy similares, y no hay diferencias estadísticamente significativas, aunque las mujeres muestren mayor capacidad de regulación emocional que los hombres, diferencias que sí fueron estadísticamente significativas $(\mathrm{t}=0,351, \mathrm{p}=0,726)$. En conclusión, ambos grupos presentan una buena inteligencia experiencial y emocional.

\begin{tabular}{|l|c|c|c|c|c|l|}
\hline & \multicolumn{2}{|c|}{$\begin{array}{c}\text { Hombres } \\
(\mathbf{n = 5 9 )}\end{array}$} & \multicolumn{2}{c|}{$\begin{array}{c}\text { Mujeres } \\
(\mathbf{n = 1 0 0}\end{array}$} & & \\
\hline Escalas del CTI & Media & SD & Media & SD & $\mathbf{t}^{\mathbf{1}}$ & $\mathbf{p}^{\mathbf{2}}$ \\
\hline PCG. Pensamiento constructivo & 50,9 & 10,9 & 51,5 & 9,6 & $-0,351$ & 0,726 \\
\hline EMO. Afrontamiento emocional & 49,1 & 10,2 & 50,3 & 9,5 & $-0,720$ & 0,473 \\
\hline CON. Afrontamiento conductual & 51,5 & 10,0 & 50,6 & 10,1 & 0,573 & 0,567 \\
\hline MAG. Pensamiento mágico & 47,7 & 10,2 & 48,6 & 10,3 & $-0,498$ & 0,619 \\
\hline CAT. Pensamiento categórico & 46,0 & 11,3 & 49,3 & 11,3 & $-1,743$ & 0,083 \\
\hline ESO. Pensamiento esotérico & 54,1 & 8,7 & 53,7 & 8,3 & 0,262 & 0,794 \\
\hline OPT. Optimismo ingenuo & 52,8 & 9,8 & 53,6 & 11,9 & $-0,425$ & 0,671 \\
\hline
\end{tabular}

Tabla 1: Diferencias de medias entre hombres y mujeres en el inventario de pensamiento constructivo (CTI)

En función de las escalas, los hombres obtuvieron puntuaciones que van desde 49,1 (SD = 10,2) en afrontamiento emocional hasta 54,1 ( $\mathrm{SD}=8,7)$ en pensamiento esotérico. Las puntuaciones de las mujeres oscilan entre 48,6 (SD = 10,3) en pensamiento mágico hasta $53,7(\mathrm{SD}=8,3)$ en pensamiento esotérico. Tanto los chicos como las chicas muestran tendencia a creer en fenómenos extraños, mágicos y científicamente cuestionables, tales como los fantasmas, la astrología y las supersticiones convencionales. Dentro de ciertos límites, el pensamiento esotérico revela simplemente una actitud propensa hacia los fenómenos inusuales y no comprobados. No obstante, puntuaciones muy altas sugerirían carencia de pensamiento crítico y una excesiva confianza en las impresiones intuitivas.

\footnotetext{
${ }^{1}$ t de Student (diferencias de medias)

${ }^{2}$ Significación estadística
} 
Tanto hombres como mujeres presentan un perfil muy similar en las escalas del CTI. No se hallan diferencias entre hombres y mujeres en las subescalas del cuestionario, ni en afrontamiento emocional $(t=-0,720, p=0,473)$, ni en afrontamiento conductual $(t=0,573, p=0,567)$, ni en pensamiento mágico $(\mathrm{t}=-0,498, \mathrm{p}=0,619)$, ni pensamiento esotérico $(\mathrm{t}=-1,743, \mathrm{p}=0,083)$, ni en optimismo ingenuo $(\mathrm{t}=-0,425, \mathrm{p}=0,671)$.

En función de la edad, en general los participantes menores presentan puntaciones globales algo más altas en el pensamiento constructivo del CTI, media de 52,9 (SD = 8,7), que los participantes mayores, media de 49,9 (SD = 10,8). Ambos grupos presentan una buena inteligencia experiencial y emocional, aunque los más jóvenes presentan mejor regulación emocional que los mayores, diferencias que son estadísticamente significativas $(\mathrm{t}=2,230, \mathrm{p}=0,027)$. En función de las escalas, los menores obtuvieron puntuaciones que van desde 48,0 $(\mathrm{SD}=9,4)$ en pensamiento mágico hasta $54,8(\mathrm{SD}=10,6)$ en optimismo ingenuo. Las puntuaciones de los mayores oscilan entre 45,8 $(\mathrm{SD}=$ 11,1) en pensamiento categórico hasta 54,2 (SD = 8,8) en pensamiento esotérico.

Tanto los jóvenes como los mayores destacan por su tendencia a tener una visión simplista de la vida y a evitar realidades desagradables, que puede llevarles a no tomar las debidas precauciones; suelen ser chicos que caen bien a los demás y muy respetuosos, con tendencia a creer en fenómenos extraños, mágicos y científicamente cuestionables, tales como los fantasmas, la astrología y las supersticiones convencionales. Son activos en la resolución de conflictos.

Se hallaron diferencias significativas entre ambos grupos de edad en pensamiento constructivo $(\mathrm{t}$ $=2,230, \mathrm{p}=0,027)$, afrontamiento emocional $(\mathrm{t}=2,630, \mathrm{p}=0,009)$ y pensamiento categórico $(\mathrm{t}=$ 2,774, $\mathrm{p}=0,006$ ), en el sentido de que los más jóvenes presentan más capacidad de autorregulación emocional que los mayores, serían menos sensibles a la crítica, errores o rechazos de sus compañeros, por lo que presentan un mejor afrontamiento emocional a los retos que afrontan y presentan más tendencia a agrupar los hechos y las personas en amplias categorías menos sofisticadas que los mayores. No se hallaron diferencias entre menores y mayores en afrontamiento conductual, pensamiento mágico, pensamiento esotérico, ni en optimismo ingenuo.

\begin{tabular}{|l|c|c|c|c|c|c|}
\hline & \multicolumn{2}{|c|}{$\begin{array}{c}\text { Menores de 13 años } \\
(\mathbf{n}=\mathbf{7 3 )}\end{array}$} & \multicolumn{2}{|c|}{$\begin{array}{c}\text { Mayores de 13 años } \\
(\mathbf{n = 8 6})\end{array}$} & & \\
\hline Escalas del CTI & Media & SD & Media & SD & $\mathbf{t}^{\mathbf{3}}$ & $\mathbf{p}^{\mathbf{4}}$ \\
\hline PCG. Pensamiento constructivo & 52,9 & 8,7 & 49,9 & 10,8 & 2,230 & 0,027 \\
\hline EMO. Afrontamiento emocional & 52,0 & 8,3 & 48,0 & 10,5 & 2,630 & 0,009 \\
\hline CON. Afrontamiento conductual & 52,5 & 9,4 & 49,7 & 10,3 & 1,767 & 0,079 \\
\hline MAG. Pensamiento mágico & 48,0 & 9,4 & 48,5 & 10,7 & $-0,306$ & 0,760 \\
\hline CAT. Pensamiento categórico & 50,7 & 11,2 & 45,8 & 11,1 & 2,774 & 0,006 \\
\hline ESO. Pensamiento esotérico & 53,4 & 8,0 & 54,2 & 8,8 & $-0,572$ & 0,568 \\
\hline OPT. Optimismo ingenuo & 54,8 & 10,6 & 52,0 & 11,5 & 1,575 & 0,117 \\
\hline
\end{tabular}

Tabla 2: Diferencias de medias entre menores y mayores en el inventario de pensamiento constructivo (CTI)

En función de los datos obtenidos con este cuestionario, los alumnos en las colonias musicales tienen tendencia a creer en supersticiones y los buenos o malos agüeros, a la vez que tienen tendencia a evitar realidades desagradables. Estas características nos hacen pensar en el necesario trabajo enfocado a afrontar el miedo escénico de una forma racional. Igualmente los asistentes a unas colonias musicales se definen como personas con tendencia a ser optimistas, a enfatizar lo positivo, a ser entusiastas y enérgicos. Todas estas cualidades, sin duda, se ven reforzadas por el ambiente distendido de unas colonias y son aplicadas y desarrolladas en el uso del role playing y el trabajo escénico.

A continuación ofrecemos los resultados relativos a las competencias sociales. Centrándonos ahora en la descripción de las puntuaciones del test de empatía cognitiva y afectiva (TECA), los 182 participantes que cumplimentaron este cuestionario obtuvieron una puntuación centil global en el

\footnotetext{
3 t de Student (diferencias de medias)

${ }^{4}$ Significación estadística
} 
TECA de 48,21 (SD = 24,62) lo que indica que se autodefinen como personas con una buena capacidad de autorregulación emocional. Si observamos las puntuaciones apreciamos que se produce una gran dispersión en los resultados dados por los estudiantes en un rango de 2 a 99, es por ello que obtenemos una media de 48,21 pero la mayoría de estudiantes (moda) obtienen una puntuación alrededor de 40 en el TECA.

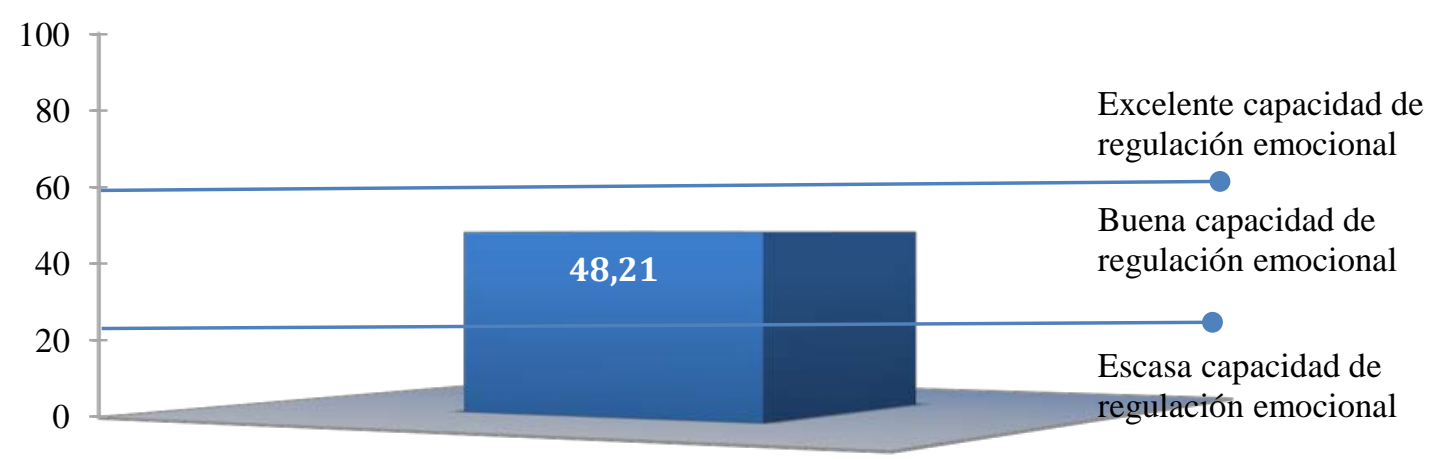

Fig. 15: Índice global en el test de empatía cognitiva y afectiva (TECA)

En la siguiente figura reflejamos como los participantes obtuvieron un puntuación de 49,24 (SD = 27,37) en la escala de adopción de perspectivas; de 56,73 (SD = 25,75) en la escala de comprensión empática, de 44,98 (SD = 23,37) en la escala de estrés empático y de 44,85 (SD = 27,72) en la escala de alegría empática. En general, los participantes mostraron puntuaciones más altas en comprensión empática y adopción de perspectivas, lo cual indica una buena comprensión de las necesidades de los compañeros, así como una buena colaboración entre ellos.

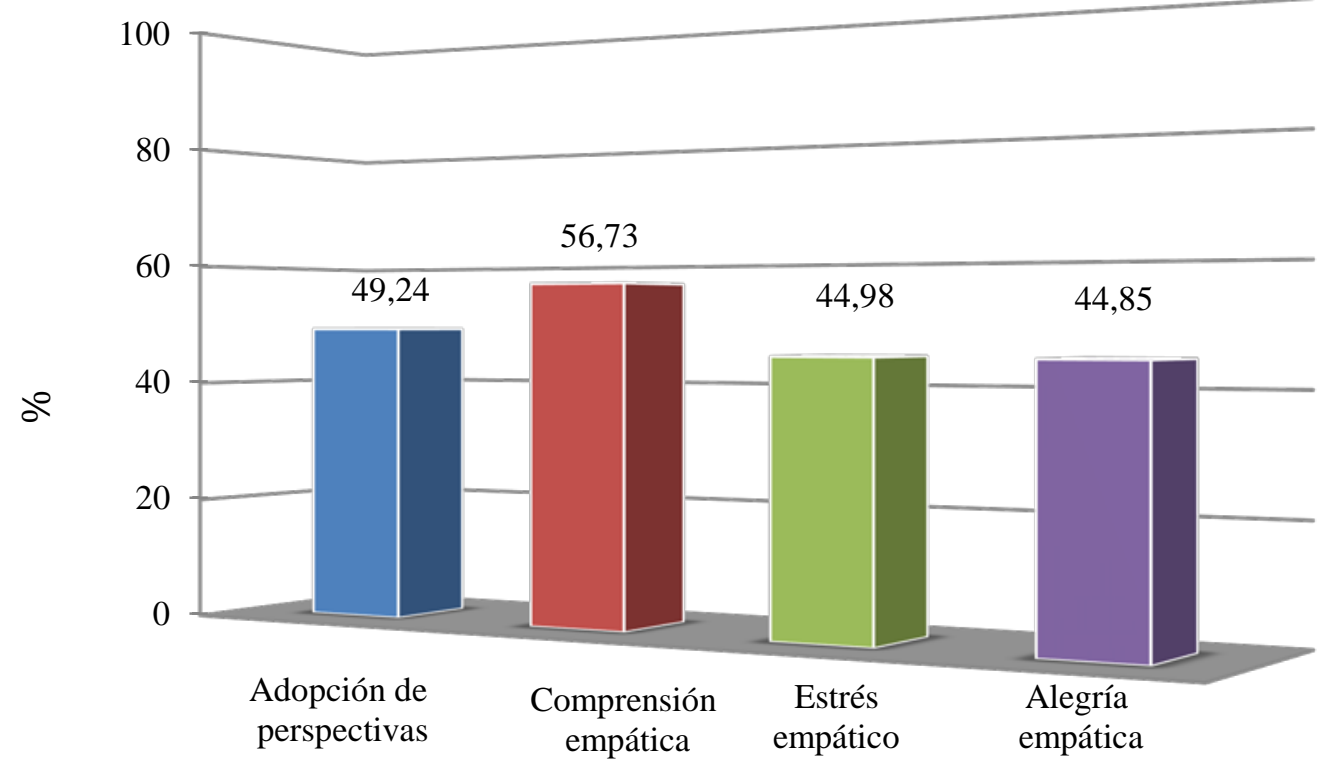

Fig. 16: Puntuaciones centiles en las escalas del test de empatía cognitiva y afectiva (TECA)

Si nos centramos en las diferencias en función del género, en general las mujeres presentan puntaciones globales más altas en el TECA, media de 51,9 (SD = 25,2), que los hombres, media 41,9 $(\mathrm{SD}=22,3)$. Las mujeres muestran mayor capacidad de regulación emocional que los hombres, diferencias que no son estadísticamente significativas $(\mathrm{t}=-2,6969, \mathrm{p}=0,008)$. 
En función de las escalas, los hombres obtuvieron puntuaciones que van desde 36,7 (SD = 25,4) en alegría empática, hasta 55,3 (SD = 26,7) en comprensión empática. Las puntuaciones de las mujeres oscilaron entre 49,4 (SD = 27,9) en adopción de perspectivas, hasta 57,2 (SD = 25,2) en comprensión empática.

Tanto los chicos como las chicas muestran buena capacidad para reconocer y comprender los estados emocionales de los demás. Existen diferencias entre hombres y mujeres en estrés empático ( $\mathrm{t}=-3,702, \mathrm{p}=0,0001)$, en alegría empática $(\mathrm{t}=-3,111, \mathrm{p}=0,002)$, y en el índice global de empatía $(t=-2,696, p=0,008)$, es decir, las mujeres muestran más capacidad empática que los hombres pero, esta mayor capacidad podría dar lugar a una mayor implicación en los problemas y circunstancias de los compañeros, tanto para lo bueno como para lo malo. Las chicas podrían experimentar mayor alegría por las cosas buenas que les suceden a sus amigos/as pero también sufrirían más con las cosas no tan buenas. No se hallaron diferencias entre ambos géneros en adopción de perspectivas y comprensión empática.

\begin{tabular}{|l|l|l|l|l|l|l|}
\hline & \multicolumn{2}{|c|}{$\begin{array}{c}\text { Hombres } \\
\text { (n= 68) }\end{array}$} & \multicolumn{2}{|c|}{$\begin{array}{c}\text { Mujeres } \\
(\mathbf{n = 1 1 4 )}\end{array}$} & & \\
\hline Escalas del TECA & Media & SD & Media & SD & $\mathbf{t}^{\mathbf{5}}$ & $\mathbf{p}^{\mathbf{6}}$ \\
\hline Adopción de perspectivas & 48,8 & 26,5 & 49,4 & 27,9 & $-0,155$ & 0,877 \\
\hline Comprensión empática & 55,3 & 26,7 & 57,5 & 25,2 & $-0,553$ & 0,581 \\
\hline Estrés empático & 36,9 & 21,2 & 49,7 & 23,3 & $-3,702$ & 0,0001 \\
\hline Alegría empática & 36,7 & 25,4 & 49,6 & 28,1 & $-3,111$ & 0,002 \\
\hline Índice global de empatía & $\mathbf{4 1 , 9}$ & $\mathbf{2 2 , 3}$ & $\mathbf{5 1 , 9}$ & $\mathbf{2 5 , 2}$ & $\mathbf{- 2 , 6 9 6}$ & $\mathbf{0 , 0 0 8}$ \\
\hline
\end{tabular}

Tabla 3: Diferencias de medias entre hombres y mujeres en el Test de Empatía Cognitiva y Afectiva (TECA)

La empatía, y los datos aquí reflejados, muestran como, en el caso de las colonias, un ambiente lleno de confesiones y de amistades inseparables a lo largo de éstas, el nivel empático es correcto. Debemos recordar que la mayoría del trabajo musical que se realiza en estas colonias es grupal, por lo que la empatía pasa a un primer plano de importancia al, por ejemplo, necesitar conocer el estado anímico de un solista en un combo para poder acompañarle correctamente en su improvisación.

La empatía es importante para los futuros músicos, pues permite comprender las necesidades de los compañeros y aproximarse a los demás de forma eficaz. Sin embargo, puntuaciones muy elevadas en estrés empático dificultarían la objetividad profesional e interferirían negativamente en el bienestar de los participantes (Batson, Batson, Brummett, Shaw y Aldeguer, 1995), llegando incluso a tomar decisiones erróneas (Oceja, 2008).

Por último, y analizando las respuestas derivadas del cuestionario de capacidad de liderazgo (LID), los 179 participantes obtuvieron una puntuación directa global en el cuestionario de liderazgo de 36,78 ( $\mathrm{SD}=7,9)$ lo que indica que se autodefinen como personas con una buena capacidad de liderazgo.

\footnotetext{
${ }^{5}$ t de Student (diferencias de medias)

${ }^{6}$ Significación estadística
} 


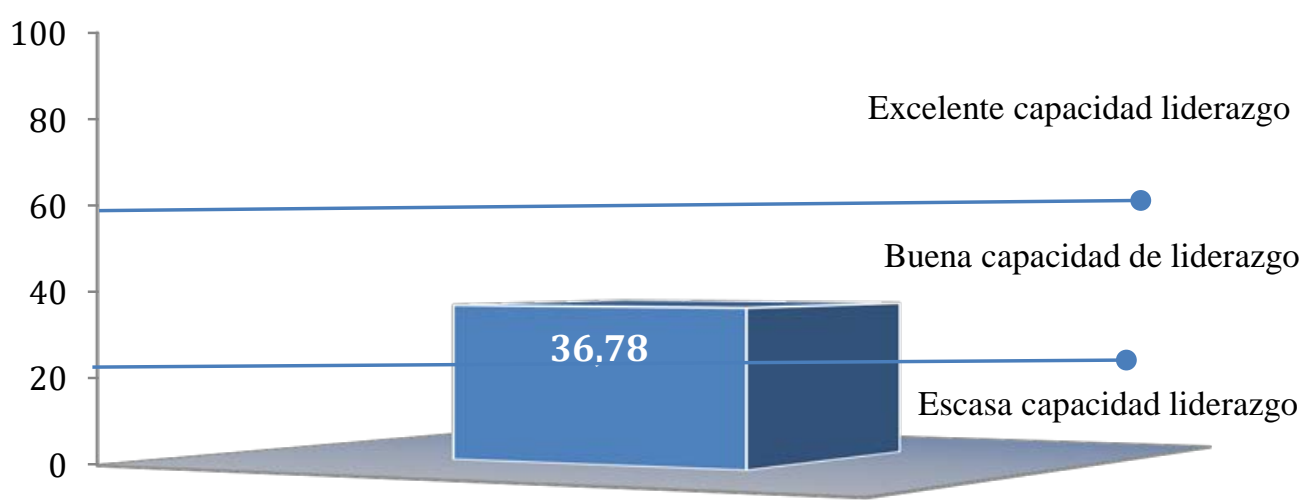

Fig. 17. Puntuaciones directas de índice global de Liderazgo (LID)

En función de la puntuación obtenida, el 64,2\% $(n=115)$ de los participantes no muestran capacidad de liderazgo pero tampoco una actitud pasiva o insegura, son personas con iniciativa propia, pero no para influir a los demás de modo suficiente; el 34,1\% (n =61) de los participantes muestran capacidad de liderazgo, con capacidad de dotes de mando, seguros de sus propias conclusiones, con buena capacidad de iniciativa e influencia en el resto de sus compañeros; y el 1,7\% $(n=3)$ de los participantes no muestran capacidad de liderazgo, carecen de dotes de mando, esta falta de iniciativa podría deberse por falta de capacidad para asumir tal responsabilidad o por su forma de ser.

\begin{tabular}{|l|c|c|}
\hline Escalas del LID & Frecuencia & Porcentaje \\
\hline Excelente capacidad de liderazgo & 61 & 34,1 \\
\hline Buena capacidad de liderazgo & 115 & 64,2 \\
\hline Escasa capacidad de liderazgo & 3 & 1,7 \\
\hline
\end{tabular}

Tabla 4: Descriptivo del Cuestionario de capacidad de Liderazgo (LID)

En función del género, en general, los hombres presentan puntaciones globales más altas en el LID, media de 38,6 (SD = 7,3), que las mujeres, media 35,6 (SD = 8,0). En ese sentido, los hombres muestran mayor capacidad de liderazgo que las mujeres, diferencias que son estadísticamente significativas $(\mathrm{t}=2,484, \mathrm{p}=0,014)$.

En función de la edad, en general, los menores de 13 años presentan puntaciones globales similares en el LID, media de 37,0 (SD = 7,9), a las puntuaciones obtenidas por los mayores de 13 años, media 36,5 (SD = 7,9). Tanto los mayores como los menores, en conjunto, muestran iniciativa aunque no capacidad de liderazgo; las diferencias entre ambos grupos no son estadísticamente significativas ( $\mathrm{t}$ $=0,376, \mathrm{p}=0,708$ ).

Las puntuaciones derivadas de este cuestionario, implican que los alumnos que acuden a unas colonias musicales, a pesar de no destacar en ello, se sienten cómodos ante la adopción del papel de líder. Si pensamos, por ejemplo, en los instrumentos solistas, o un cuarteto de cámara en el que las voces se reparten la melodía principal durante toda la obra; dicho liderazgo momentáneo resulta crucial. Además, el trabajo en pequeños grupos rotatorios obliga a contar con múltiples líderes ocasionales.

Un buen líder musical, además de tener una buena formación respecto a los conocimientos propios de cada especialidad instrumental, también debe poseer una buena formación emocional, formación que se adquiere a través de la llamada "educación emocional”. La autoconciencia emocional, la autorregulación, la conciencia social y la gestión de las relaciones son los pilares fundamentales sobre los que se sustenta esta educación (Goleman, 2014). El conocimiento profundo y la práctica de estas competencias ayudarán al buen líder en su tarea, capacitándole para saber escoger cuál es la tipología 
de liderazgo más adecuada en cada situación. En el caso de un director musical y sus músicos -icono del liderazgo- vemos cómo el éxito que obtiene en los conciertos es fruto, no solo del trabajo musical, sino también del talante del buen líder, que será capaz de conseguir que todos se sientan realizados como músicos y como parte importante del grupo.

\section{CONCLUSIONES}

En función de todo lo descrito hasta ahora, podemos realizar un perfil personal y competencial tipo de los asistentes a una colonia musical. Nuestra alumna tipo tiene una buena autoestima y es una persona empática. Es una persona moderadamente creativa, a la vez que presenta una buena capacidad en pensamiento constructivo. Finalmente, muestra una buena capacidad de liderazgo.

En conclusión, tal como muestran los instrumentos de recogida de datos aplicados, los asistentes a las colonias musicales muestran un perfil competencial con puntuaciones dentro del rango de la normalidad.

Por lo tanto, a pesar de que el alumnado descrito no presenta grandes carencias ni personales ni sociales, consideramos que se debería incidir e incluir más actividades que desarrollasen la creatividad y el liderazgo debido a las características organizativas del contexto de las colonias musicales. Dichas actividades han de partir de la diferenciación existente entre unas colonias musicales y el resto de actividades educativas musicales, es decir: la colectividad, la convivencia y las actividades de ocio complementarias.

En base a esto proponemos una reformulación en la cual tome más importancia dichas particularidades. Así pues, proponemos un cambio en el horario en el cual se combinen continuamente las clases de música y las actividades de ocio (por ejemplo una hora y media de clase de música seguida de una hora de actividad de ocio, y así hasta completar las cinco horas de clase de música diarias habituales en unas colonias, lo que a su vez supondría casi cuatro horas de actividades de ocio programadas dividas en tres franjas diferenciadas).

En dichas actividades de ocio se debería trabajar el desarrollo competencial, haciendo especial hincapié en, por ejemplo, las formaciones musicales preexistentes en cada una de las clases (es decir, el grupo de combo iría siempre junto en algunas de las actividades, el grupo de guitarras igual, el grupo de vientos lo mismo, etc.). De esta forma se atribuirían los papeles de líder de cada grupo en las actividades a los líderes ocasionales del fragmento musical que se estuviese trabajando en la clase. En estas actividades lúdicas se podría realizar un trabajo escénico no musical, ya sea a través de la interpretación de teatrillos o parodias de forma que se incidiese en el miedo escénico. Además de esto, si dichas representaciones fueran totalmente diseñadas por el alumnado se podría fomentar el desarrollo de su propia creatividad.

Para el desarrollo de dicha creatividad en las colonias musicales se propone la práctica de algunas de las técnicas más habituales al respecto (Gustems, 2013), mediante la orientación y guía de los profesores o tutores de grupo ante situaciones complejas que se presenten en la toma de decisiones, como por ejemplo: el SCAMPER (substituir, combinar, adaptar, modificar, buscar otros usos, eliminar, cambiar la forma), el brainstorming (o lluvia de ideas a partir de una situación, tema o problema, desarrolla la fluidez, el análisis y la valoración posterior de los resultados obtenidos), la metáfora (como herramienta de creación y de asociación de ideas), las analogías, los cambios de registro con resultados novedosos, las asociaciones remotas, el concassage (someter una idea a un aumentación, disminución, mejora, asociación, inversión, supresión, etc. valorando la originalidad de los resultados obtenidos), considerar lo contrario para hacer la síntesis de opuestos, la solución de problemas con un cambio de perspectiva y abrir vías para la creación de nuevos productos, la Sinéctica (reunión de elementos que no guardan relación aparente y que se intenta buscar), los juegos, la imprenta, la radio, el blog, la improvisación y actividades derivadas de la matriz combinatoria de Guilford (que combina 4 tipos de contenidos -figurativo, simbólico, semántico o conductual-, 6 
productos -unidad, clase, relación, sistema, transformación e implicación- resultando 24 tipos diferentes de propuestas creativas).

Para el desarrollo del liderazgo, siguiendo a Goleman (2014) se propone tomar conciencia en la preparación de ensayos y conciertos, mediante reuniones de equipo donde se comente la autoconciencia emocional con los propios valores, la coherencia, franqueza, capacidad de evaluación realista, motivación por el trabajo, sentido del humor autocritico, evitar correr riesgos innecesarios, pedir ayuda, crear entornos de confianza, conciencia social empática y organizativa, influencia, gestión de los conflictos, trabajo en equipo y colaborativo, autocontrol emocional, adaptabilidad ante los cambios y capacidad de triunfo. Todos estos aspectos pueden ser observados mediante reuniones supervisadas por un tutor donde los miembros de cada grupo puedan expresar libremente sus sensaciones en los ensayos. Asimismo sería conveniente poder ejercer algunos tipos de rotación de roles intragrupo e intergrupos para descubrir potencialidades y capacidades adaptativas de los mismos (Belbin, 1995).

Además de lo descrito, proponemos cambios dentro de las actividades musicales, de forma que el alumnado pase por varias agrupaciones diferentes y diversos compañeros en las mismas (por ejemplo el grupo de cuerda funcionase junto durante dos días y luego mezclarlo con diferentes instrumentistas de viento para hacer un trabajo de cámara). De esta forma, el trabajo en pro del desarrollo competencial se vería reforzado al poner a cada alumno en diversas situaciones musicales y por consiguiente de tiempo libre. Dicho refuerzo vendría marcado por la diversidad de grupos y, en definitiva, no facilitar la endogamia que puede presentarse al estar el alumnado siempre en el mismo grupo y rodeado de los mismos instrumentistas y compañeros. De esta forma se ampliará su círculo de amistades y de relaciones interpersonales, lo cual supone, a su vez, una autoafirmación y desarrollo de su propia personalidad. A través de estos cambios, u otros similares, las colonias musicales obtendrían unos resultados educativos que podríamos calificar de como excelentes y que serían objetivo a alcanzar y modelo para otros ámbitos de la educación no formal.

\section{Referencias}

Alonso Monreal, C. (2000). Qué es la creatividad. Madrid: Biblioteca Nueva.

Álvarez, M. (2001). El liderazgo de los procesos de mejora. En Cantón, I. (Ed.), La implantación de la calidad en los centros educativos. Madrid: CCS.

Atienza, F. L., Moreno, Y., \& Balaguer, I. (2000). Análisis de la dimensionalidad de la Escala de Autoestima de Rosenberg en una muestra de adolescentes valencianos. Revista de Psicología. Universitas Tarraconensis, XXII(1-2), 29-42.

Ávila de Encío, M. C. (2010). Cuestionario de capacidad de liderazgo. Consultado en http://www.google.com/search?q=liderazgo+carmen+avila+de+encio+\&sourceid=ie7\&rls=c om.microsoft:en-US\&ie=utf8\&oe=utf8\&rlz=1I7GGLL_esES310 el 10/IX/2015.

Baños, R. M. \& Guillén, V. (2000). Psychometric characteristics in normal and socialphobic samples for a Spanish version of Rosenberg Self-Esteem Scale. Psychological Reports, 87, 269-274.

Batson, C. D., Batson, J. G., Todd, R. M., Brummett, B. H., Shaw, L. L., \& Aldeguer, C. M. R. (1995). Empathy and the collective good: caring for one of the others in a social dilemma. Journal of Personality and Social Psychology, 68(4), 619-631.

Belbin, R. M. (1995). Roles de equipo en el trabajo. Bilbao: Universal.

Bisquerra Alzina, R., \& Pérez Escoda, N. (2007). Las competencias emocionales. Educación XXI, 10, 61-82.

Calderón, D. (2013). Ocio y música para jóvenes: Una educación creativa. En J. Gustems (Ed.), Creatividad y educación musical: Actualizaciones y contextos. Barcelona: DINSIC. 
Calderón, D., Gustems, J., \& Calderón C. (2014). Colonias musicales: Análisis y objetivos didácticos. Música y Educación, 98, 32-38.

Cano, E. (2005). Cómo mejorar las competencias de los docentes. Guía para la autoevaluación y el desarrollo de las competencias del profesorado. Barcelona: Graó.

Colomer, J. (1975). Radiografía de un centro de tiempo libre. Cuadernos de Pedagogía, 7, 35-39.

Corbalán, F. J., Martínez, F., Donolo, D., Tejerina, M., \& Limaña, R. M. (2003). CREA. Test de Evaluación de la Inteligencia Creativa. Una medida cognitiva de la creatividad. Madrid: TEA Ediciones.

Dalia, G. (2008). Cómo ser feliz si eres músico o tienes uno cerca. Madrid: Mundimúsica.

Davis, S. G. (2005). That thing you do! Compositional processes of a rock band. International Journal of Education \& the Arts, 6(16), 1-18.

Epstein, S. (2001). Inventario de pensamiento constructivo (evaluación de la inteligencia emocional) (CTI). Madrid: TEA.

Generalitat de Catalunya (2007). Decret 142/2007. DOGC nº 4915, p. 21822-21870.

Giráldez, A. (2011). Educación musical y competencias transversales. Aula de Innovación Educativa, 200, 36-39.

Goleman, G. (1995). Emotional intelligence. Nueva York: Bantam.

Goleman, D. (2014). Liderazgo. El poder de la inteligencia emocional. Barcelona: Ediciones B.

Gustems, J. (2013). Creatividad y educación musical: Actualizaciones y contextos. Barcelona: Dinsic.

Gustems, J., \& Calderón, C. (2005). No t’emocionis... Escolta! L’ús de la música en l’educació emocional. Revista Catalana de Pedagogia, 3, 331-347.

Hargreaves, D. J., \& North, A. C., (1999). The functions of music in everyday life: Redefining the social in music psychology. Psychology of Music, 27(1), 71- 83.

Hollingshead, A. A. (1975). Four-factor index of social status. New Haven: Yale University.

Comisión Nacional para la Protección de los Sujetos Humanos de Investigación Biomédica y del Comportamiento (1978). El informe Belmont, Principios y guías éticos para la protección de los sujetos humanos de investigación. Consultado en http://bioeticayderecho.ub.es el 12/V/2015.

Letourneau, C. (1981). Empathy and stress: How they affect parental aggression. Social Work, 26, 383-389.

Lamont, A. (2012). Emotion, engagement and meaning in strong experiences of music performance. Psychology of Music, 40(5), 574-594.

LOE, Ley Orgánica 2/2006 (2006). BOE n¹06, 17158-17207.

López-Pérez, B., Fernández-Pinto, I., \& Abad, F. J. (2008). TECA. Test de empatía cognitiva y afectiva. Madrid: TEA.

Oceja, L. (2008). Overcoming Empathy-Induced Partiality: Two rules of Thumb. Basic and Applied Social Psychology, 30(2), 176-182. doi: http://psycnet.apa.org/doi/10.1080/01973530802209 236

Oceja, L. V., López Pérez, B., Ambrona, T., \& Fernández, I. (2009). Measuring general dispositions to feel empathy and distress. Psicothema, 21, 171-176.

Parcerisa, A. (2007). Las competencias como referentes para la práctica educativa. Eufonía: Didáctica de la música, 41, 6-16. 
Pastor, Y., Balaguer, I., \& García-Merita, M. (2006). Relaciones entre el autoconcepto y el estilo de vida saludable en la adolescencia media: un modelo exploratorio. Psicothema, 1(1), 18-24.

Perrenoud, P. (2007). Diez nuevas competencias para enseñar. Barcelona: Graó.

Rosenberg, M. (1989). Society and the adolescent self-image. Middeltown: Wesleyan University Press.

Runco, M. A. (2010). Parsimonious creativity and its measurement. En E. Villalba (Ed.), Measuring creativity: The book. Consultado en http://ec.europa.eu/education/lifelong-learningpolicy/doc2082_en.htm el 09/VI/2015.

Rusinek, G. (2006). Aprendizaje musical significativo. Revista Electrónica Complutense de Investigación en Educación Musical, 1(5), 1-6.

Souza, L. (2009). Competencias emocionales y resolución de conflictos interpersonales en el aula. Tesis doctoral. Universidad Autónoma de Barcelona.

Sternberg, R. \& Lubart, T. (1997). La creatividad en la cultura conformista. Un desafío a las masas. Barcelona: Paidós.

Trusty, J. \& Oliva, J. (1994). The effects of arts and music education on students' selfconcepts. Applications of Research in Music Education, 13, 23-28.

Varvaigou, M. \& Durrant, C. (2011). Theoretical perspectives on the education of choral conductors: A suggested framework. British Journal of Music Education, 28(3), 325-338.

Wylie, R. C. (1989). Measures of self-concept. Lincoln: Buros Institute of Mental Measurements. 